\title{
Screening for hepatocellular carcinoma: patient selection and perspectives
}

\section{Waleed Fateen \\ Stephen D Ryder}

NIHR Biomedical Research Unit in Gastrointestinal and Liver Diseases, Nottingham University Hospitals NHS Trust, The University of Nottingham, Nottingham, UK
Correspondence: Stephen D Ryder Nottingham Digestive Disease Unit, D Floor, South block, Queens Medical Centre, Nottingham, UK, NG7 2UH

Tel +44 II 59249924

Fax +44 II 59709012

Email Stephen.Ryder@nuh.nuhs.uk
This article was published in the following Dove Press journal:

Journal of Hepatocellular Carcinoma

17 May 2017

Number of times this article has been viewed

Abstract: Hepatocellular carcinoma (HCC) develops on the background of liver cirrhosis often from multiple, simultaneous factors. The diagnosis of a single small HCC comes with good prognosis and provides a potential for cure. In contrast, the diagnosis of multifocal, large HCC has high mortality and poor prognosis. Unfortunately, the majority of $\mathrm{HCC}$ is diagnosed at such late stages. A surveillance program endorsed by regional liver societies involves six-monthly ultrasound surveillance of at-risk patients. This had been in action for the last two decades. It has led to marked increase in the proportion of patients presenting with small unifocal nodules found on surveillance. The development of tools to enhance our ability in optimizing available surveillance is likely to improve the prognosis of patients with HCC. In this review, we discuss the difficulties in utilizing HCC surveillance and possible means of improvement.

Keywords: hepatocellular carcinoma, surveillance, screening, risk stratification

\section{Introduction}

Hepatocellular carcinoma (HCC) is a global health problem. It is the second most common cause of cancer-related mortality and the sixth most common cause of cancer worldwide. ${ }^{1}$ This discrepancy between incidence and mortality emphasizes the aggressive nature and poor prognosis of this tumor. $\mathrm{HCC}$ has the fastest rising tumor incidence in the west. ${ }^{2,3}$ This is partly related to the rising epidemic of its triggers, such as fatty liver, alcohol, and viral hepatitis.

The process of hepatocarcinogenesis starts with one or more triggering factors causing inflammation and fibrosis of what was previously a normal liver. As fibrosis becomes advanced, the risk of developing cancer gets higher. Eventually with ongoing liver cell injury, a focus of dysplasia arises within a genetically and immunologically susceptible liver as demonstrated in Figure 1. This may develop into a dysplastic nodule and subsequently HCC.

The triggers vary in intensity and in their ability to cause cancer. Hepatitis B virus (HBV) is thought to be the most carcinogenic trigger as the DNA of the virus integrates with host genome. It is the most common cause of HCC in the East, but is rarely seen in the Western world especially with better control of viral replication using nucleotide and nucleoside inhibitors. Hepatitis $\mathrm{C}$ virus (HCV) remains the most common cause of HCC in the Western world. The mechanism by which this RNA virus leads to cancer remains largely unknown, but in theory is attributed to chronic inflammation caused by the virus. Recent advances in the treatment of HCV using directly acting antiviral agents (DAAs) may have large consequences on the landscape 


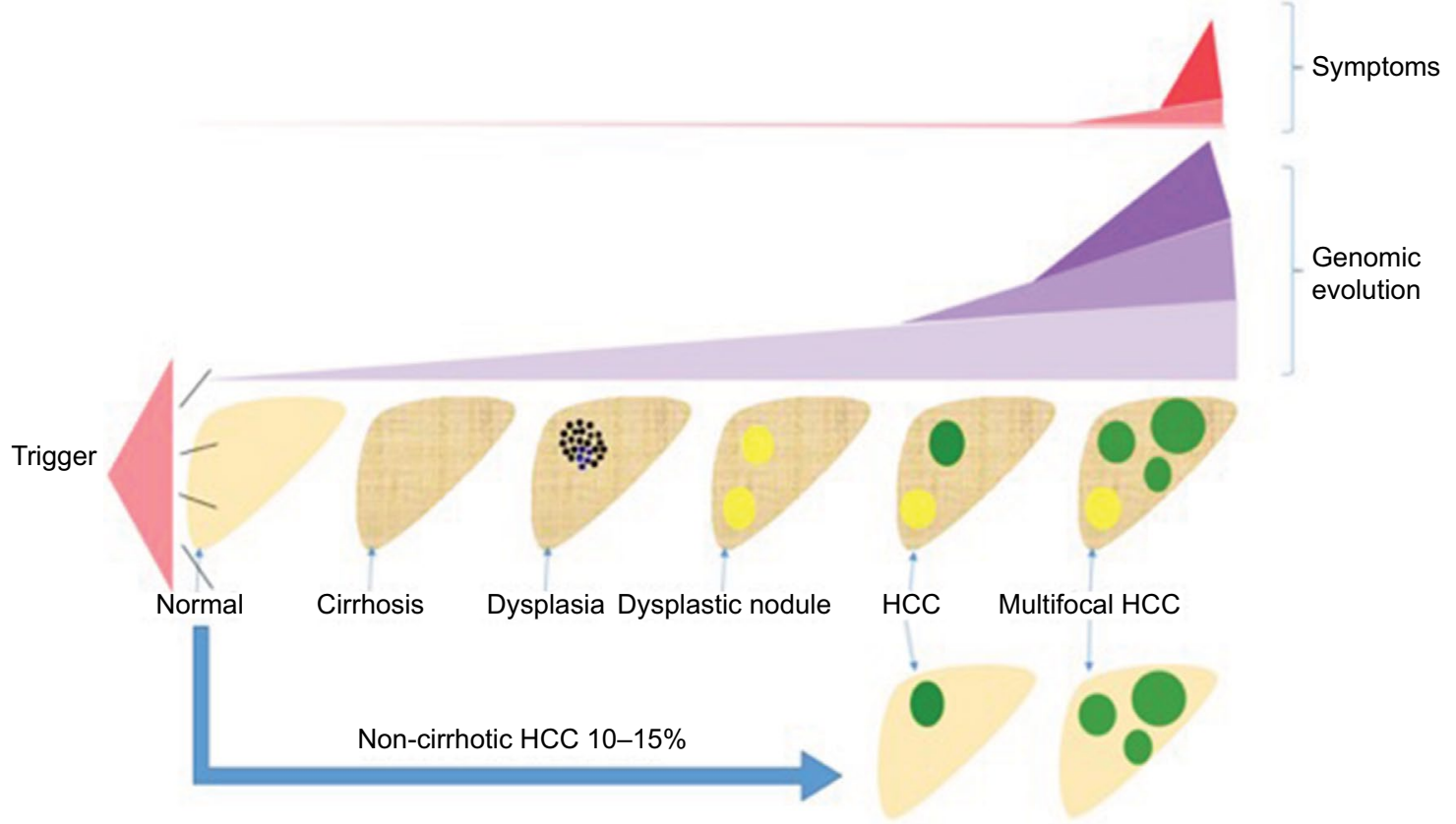

Figure I Natural history of HCC demonstrating the journey of a liver as it goes through cirrhosis, dysplasia, carcinoma, and multifocal cancer. Notes: The parallel symptoms and known genomic features take a much more subtle course at the early stages and intensifies at the late stage. Abbreviation: $\mathrm{HCC}$, hepatocellular carcinoma.

of HCC epidemiology. Recently, multiple reports indicating unexpectedly non-diminishing and possibly increasing rates of HCC occurrence after successful eradication of HCV by DAAs had been published. ${ }^{4-7}$ However, data from the English Expanded Access Program showed no increase in liver malignancy post treatment with DAA. ${ }^{8}$ More evidence regarding the risk of $\mathrm{HCC}$ in cirrhotic patients with no history of cancer and treatment by non-interferon-based therapies is currently awaited. Nonalcoholic steatohepatitis (NASH) and alcoholrelated liver injury remain very common causes of HCC in the Western hemisphere. They are expected to become the most common causes of HCC in the future.

HCC runs an essentially subclinical course (Figure 1). Patients tend to present at late stages when symptoms arise with subsequent poor prognosis. The known genomic changes in early HCC are subtle in comparison to advanced disease. This has led to difficulties in discovering novel genomicbased diagnostic biomarkers.

\section{Who is at risk and should be under regular surveillance?}

The risk of $\mathrm{HCC}$ varies on patient by patient basis. The single most important risk factor in the development of HCC is the presence of liver cirrhosis. HCC risk increases as more triggers are acquired, for example, fatty liver disease, increased alcohol intake, or exposure to aflatoxin. Similarly, as age and stage of fibrosis advance, the risk increases particularly in males. It is difficult to design a one-size-fits-all package for calculating risk and therefore the potential need for surveillance because the epidemiology relating to potential etiology varies globally. Similarly, the threshold for cost effectiveness of screening may vary according to the national economic situation.

\section{HCC risk stratification models}

Risk stratification models aim to rationalize surveillance decisions according to the predicted risk of developing HCC. The majority of risk stratification models have been developed using regression analysis of large retrospective cohorts of patients who developed HCC. Many of which were developed in the context of a unique risk factor, for example, hepatitis $\mathrm{B}$ or $\mathrm{C}$ virus infection.

\section{HCC risk stratification models in HBV infection}

The initial systems were developed in the East in the context of endemic HBV and were focused on this viral etiology alone. They gave high weight to HBV DNA levels and were developed prior to widespread use of nucleot(s)ide inhibitors. The initial two scoring systems, GAG-HCC (Guide with Age, Gender, HBV DNA, Core promoter mutations and Cirrhosis $)^{9}$ and CU-HCC (Chinese University-HCC),$^{10}$ were similar in content. These were followed by the REACH-B (Risk Estimation for 
Hepatocellular Carcinoma in Chronic Hepatitis B) scoring system that was developed based on data from 3,584 patients included in the Risk Evaluation of Viral Load Elevation and Associated Liver Disease/Cancer - Hepatitis B Virus-HBV study and validated on a large cohort by the same group. ${ }^{11}$ They were developed using similar methodologies with multivariate analysis of possible predictors of development of HCC in large retrospective cohorts of $\mathrm{HBV}$ patients followed by validation in separate cohorts. The three above scores had many similarities, including age, gender, and HBV DNA.

More recently, stage of fibrosis measured using noninvasive markers had been incorporated into the scoring systems. Transient elastography (TE) or acoustic radiation frequency index has shown promising potential in predicting HCC. The efforts started by the modification of the CU-HCC score by the same authors to include liver stiffness measurement (LSM) instead of subjective ultrasound scan (U/S) interpretation of possible cirrhosis. ${ }^{12}$ Liver stiffness was added to the other variables including HBV DNA. Later on, the REACH-B score was also modified to include liver stiffness instead of HBV DNA for patients achieving complete viral response on therapy. ${ }^{13} \mathrm{~A}$ study comparing all the above risk stratification systems on a large retrospective cohort found the modified REACH-B score to be the best predictor of HCC for patients on antiviral therapy treated according to guidelines set by the Korean Association for the study of the Liver. ${ }^{14}$ More recently, the PAGE-B (platelets, age, gender-HBV) model was specifically developed on a large Caucasian population with $\mathrm{HBV}$ and on either tenofovir or entecavir for $>1$ year. The model includes neither measures of fibrosis nor DNA levels. It simply relies on age, gender, and platelets. It showed very high negative predictive value. ${ }^{15}$ Further validation on independent data sets is still required. Table 1 summarizes the key components of HBV-related HCC risk, stratification systems, and mREAC.

\section{$\mathrm{HCC}$ risk stratification in $\mathrm{HCV}$ infection}

There are currently four HCC prediction models developed exclusively in the context of HCV infection. The most recent model was prospectively developed and validated on a French HCV-related compensated cirrhotic cohort of patients $(n=1,323)$. The Cox proportional hazards model was used to identify factors significantly associated with subsequent development of HCC. These included age, past alcohol intake, platelet count, gamma-glutamyltransferase, and non-sustained virological response during the study period (Table 2 ). The cohort included patients treated by interferon and others treated by DAAs. The authors suggest that after further necessary validation, the model can be utilized to stratify $\mathrm{HCV}$
Table I Key components of the recent HBV-related HCC risk stratification systems

\begin{tabular}{|c|c|c|c|}
\hline Criteria & mREACH-B & $\begin{array}{l}\text { LSM-HCC } \\
\text { mCU-HCC }\end{array}$ & PAGE-B \\
\hline \multirow[t]{7}{*}{ Age (years) } & 30-34: 0 & $<5$ I: 0 & 16-29: 0 \\
\hline & 35-39: I & $>50: 10$ & 30-39: 2 \\
\hline & 40-44: 2 & & 40-49: 4 \\
\hline & 45-49: 3 & & 50-59: 6 \\
\hline & 50-54: 4 & & 60-69: 8 \\
\hline & 55-59: 5 & & $\geq 70:$ I \\
\hline & $60-65: 6$ & & \\
\hline \multirow[t]{2}{*}{ Gender } & Male: 2 & NA & Female: 0 \\
\hline & Female: 0 & & Male: 6 \\
\hline \multirow[t]{2}{*}{ Albumin, $g / L$} & NA & $<36:$ I & NA \\
\hline & & $>35: 0$ & \\
\hline \multirow[t]{3}{*}{ Platelets, $\times 10^{9} / \mathrm{L}$} & NA & NA & $\geq 200,000: 0$ \\
\hline & & & $100,000-199,999: 6$ \\
\hline & & & $<100,000: 9$ \\
\hline \multirow[t]{3}{*}{$\mathrm{ALT}, \mathrm{U} / \mathrm{L}$} & $<15: 0$ & NA & NA \\
\hline & 15-44: I & & \\
\hline & $>44: 2$ & & \\
\hline \multirow[t]{2}{*}{$\mathrm{HBeAg}$} & Positive: 2 & NA & NA \\
\hline & Negative: 0 & & \\
\hline \multirow[t]{2}{*}{ DNA } & NA & $\leq 2 \times 10^{5} \mathrm{IU} / \mathrm{mL}: 0$ & NA \\
\hline & & $>2 \times 10^{5} \mathrm{IU} / \mathrm{mL}: 5$ & \\
\hline \multirow[t]{3}{*}{ LS (kPa) } & $<8: 0$ & $<8: 0$ & NA \\
\hline & $8-13: 2$ & 8-12: 8 & \\
\hline & $>13: 4$ & $>12: 14$ & \\
\hline Optimal cut off ${ }^{a}$ & 10 & II & 17 \\
\hline
\end{tabular}

Notes: aptimal cut-off for predicting HCC development in 5 years. Abbreviations: $\mathrm{ALT}$, alanine transaminase; $\mathrm{HBeAg}$, hepatitis $\mathrm{B}$ viral protein; $\mathrm{HCC}$, hepatocellular carcinoma; LS, liver stiffness; LSM, liver stiffness measurement; NA, not applicable; mREACH, modified REACH; mCU-HCC- modified Chinese University-HCC; PAGE-B, platelets, age, gender-HBV.

cirrhotic patients to high and low risk and prioritize available resources for surveillance accordingly. The authors did not mention specific cut offs but rather interpretation of the risk on nomogram and subsequent decision making is required. ${ }^{16}$

The earliest model analyzed a cohort of patients with advanced fibrosis and previous response failure on treatment with interferon $(n=1,005)$ included in the HALT-C (Hepatitis C Antiviral Long-Term Treatment against Cirrhosis) clinical trial. The Cox proportional hazards model was used to identify three continuous variables (age, alkaline phosphatase, and platelet count) as well as three categorical variables (black race, esophageal varices, and smoking) required to calculate the risk of HCC development. A complex equation is used for calculation (age $\times 0.049+$ black race $\times 0.712+$ alkaline phosphatase $\times 0.006+$ esophageal varices $\times 0.777+$ ever smoked $\times 0.749+$ platelets $\times-0.011)$. Interpretation of the results is similarly complex $\left(0-\log _{10}(1.50), \log _{10}(1.50)-\log _{10}(3.25)\right.$, and $>\log _{10}(3.25)$ suggest low, intermediate, and high risk, respectively). Lack of easy to use online calculators and certainly subsequent validation in the last 7 years makes its practical role near out-of-date. ${ }^{17}$ 
Table 2 Key components of the recent HCV-related HCC risk stratification systems

\begin{tabular}{|c|c|c|}
\hline Criteria & Ganne-Carrié et al ${ }^{16}$ & Chang et $\mathrm{al}^{20}$ \\
\hline \multirow[t]{2}{*}{ Age (years) } & $<50: 0$ & $<60: 0$ \\
\hline & $>50: 2$ & $>60:$ I \\
\hline \multirow[t]{3}{*}{ Platelet $\left(\times 10^{9} / \mathrm{L}\right)$} & $<100: 3$ & $<150: 1$ \\
\hline & $100-150: 2$ & $>150: 0$ \\
\hline & $>150: 0$ & \\
\hline \multirow[t]{2}{*}{ SVR } & Yes: 0 & Yes: 0 \\
\hline & No: 3 & No: 2 \\
\hline \multirow[t]{2}{*}{ Past excessive alcohol } & Yes: I & NA \\
\hline & No: 0 & \\
\hline \multirow[t]{2}{*}{ GGT } & $>$ ULN: 2 & NA \\
\hline & $<$ ULN: 0 & \\
\hline \multirow[t]{2}{*}{ Gender } & NA & Male: I \\
\hline & & Female: 0 \\
\hline \multirow[t]{2}{*}{$\operatorname{AFP}(\mathrm{ng} / \mathrm{mL})$} & NA & $>20: 1$ \\
\hline & & $<20: 0$ \\
\hline Fibrosis (biopsy) modified & NA & $0-2: 0$ \\
\hline Knodell histology index & & $3,4: 2$ \\
\hline \multirow[t]{2}{*}{ HCV genotype } & NA & Non-GTIb: 0 \\
\hline & & GTIb: 2 \\
\hline \multirow[t]{2}{*}{ Optimal cut-off } & Low $<3$, high $>8$ & 5 \\
\hline & Nomogram required & \\
\hline
\end{tabular}

Abbreviations: AFP, alpha-fetoprotein; GGT, gamma-glutamyl transpeptidase; $\mathrm{HCC}$, hepatocellular carcinoma; HCV, hepatitis B virus; SVR, sustained virologic response; ULN, upper limit of normal; NA, not applicable.

The group from Houston published analysis of data from the National Department of Veterans Affairs (VA) including 11,721 cirrhotic patients with HCV. The group aimed to enhance the performance of alpha-fetoprotein (AFP) as a diagnostic biomarker for $\mathrm{HCC}$ by incorporating other clinical and laboratory data. Serial age, platelet count, alanine transaminase (ALT) as well as the AFP/ALT and AFP/platelet value interactions had the highest impact on incorporation with serial AFP. ${ }^{18,19}$ Lack of data on response to HCV treatments if any, as well as generalizability to female non-VA cohorts maybe considered as setbacks to this approach until further validation or updates are available. The algorithm itself is complicated and requires web-based software for calculation.

Chang et al recently published data from a large retrospective cohort of HCV patients from a single center in Taiwan $(\mathrm{n}=1,879)$ who had previous treatment using interferon-based therapies. The included patients were all assessed by liver biopsy. Age, male gender, platelet count, AFP, high stage fibrosis, HCV genotype $1 \mathrm{~b}$, and non-sustained virologic response (SVR) were all independent predictors of HCC in this study population. Key components and cut off are summarized in Table 2. A cut-off score of 5 had negative and positive predictive values of $94.34 \%$ and $34.83 \%$, respectively. Generalizability to HCV patients from West treated by DAAs cannot be stipulated. Similarly, an assessment of the utility of noninvasive markers in replicating the role of liver biopsy in this context is still required. ${ }^{20}$

\section{HCC risk stratification in the context of variable risk factors}

The largest study (age, diabetes, race, etiology, gender, and severity [ADRESS]-HCC) was performed on 34,932 mostly decompensated cirrhotic patients from the US national liver transplant waiting list. The Cox proportional hazards regression model was used to identify six predictors of HCC (age, diabetes, race, etiology, sex, and severity according to ChildTurcotte-Pugh score). These were used to construct the model and this was followed by internal and external validation. The majority of patients $(45.7 \%)$ were $\mathrm{HCV}$, and other etiologies included HBV (2.8\%), NASH (17.5\%), and alcohol related $(18.3 \%)$. The algorithm is complex and requires electronic calculation, it provides the 1 -year of developing HCC. ${ }^{21}$

The Japanese group from Hyogo College of Medicine more recently developed a model (virtual touch quantification, fasting plasma glucose, male, age, AFP [VFMAP]) for all patients with liver disease. This included patients with HBV ( $\mathrm{n}=264,14.6 \%), \mathrm{HCV}(\mathrm{n}=635,35.1 \%)$, and non-B non- $\mathrm{C}(\mathrm{n}=898,49.7 \%)$. The non-B non- $\mathrm{C}$ group included modest numbers of nonalcoholic fatty liver disease $(n=96$, $5.3 \%)$ and alcohol-related liver disease $(\mathrm{n}=22,1.2 \%)$. The etiology of liver disease in the largest group $(n=724,40 \%)$ was not specified by the authors. The majority of included patients $(85.2 \%)$ were non-cirrhotic. The model includes virtual touch quantification (score 0 if $<1.33 \mathrm{~m} / \mathrm{s}$ and 1 if $>1.33 \mathrm{~m} / \mathrm{s}$ ), fasting plasma glucose (score 0 if $<110 \mathrm{mg} / \mathrm{dL}$ and 1 if $>110 \mathrm{mg} / \mathrm{dL}$ ), age (score 0 if $<55$ years and 1 if $>55$ years), gender (score 0 if female and 1 if male), and AFP (score 0 if $<5 \mathrm{ng} / \mathrm{mL}$ and 1 if $>5 \mathrm{ng} / \mathrm{mL}$ ). It showed a reassuringly high negative predictive value (98.2\%) using total cut-off score of 3 . This could be useful in excluding patients from surveillance programs when validated. ${ }^{22}$

Two general population-based HCC prediction models were developed in Japan ${ }^{23}$ and Taiwan ${ }^{24}$ where HCC is much common than in the West.

\section{Clinical guidelines}

The most recent European, Asian Pacific, and American HCC guidelines recommend that patients at higher risk of developing HCC should have regular surveillance. ${ }^{25-27}$ The guidelines currently do not incorporate risk stratification models, but this may happen in the future specially after further validation of promising models like the modified 
REACH-B and VFMAP. The guidelines refer to high risk groups as all cirrhotic patients and some non-cirrhotics as outlined in Table 3. Surveillance may not be feasible in some patients at high risk of developing HCC if they are not fit to tolerate treatment.

The guidelines specify factors influencing the risk of development of HCC in non-cirrhotic individuals to include viral hepatitis and family history of HCC; more specifically, fibrosis stage F3 and above in the case of HCV as well as race, viral replication, and age in the case of $\mathrm{HBV}$.

In summary, predicting HCC is not straightforward. It is a malignancy occurring on the background of another disease with variable triggers and increasing degrees of severity, that is, chronic liver disease. It is thus difficult to create a robust and economically feasible one-size-fits-all surveillance model. Risk stratification models are a promising tool in identifying patients at higher risk. Prospective validation of such models would justify their possible incorporation in routine clinical practice. On the basis of our collective interpretation of the published HCC risk prediction models, the following factors as summarized in Table 4 are potentially associated with increased risk.

In the meantime, regional guidance is available as outlined above to support clinical decision making. Guidelines consider cost effectiveness based on gain in life expectancy of $>3$ months with a cost of $<\$ 50,000$ per year of life saved. ${ }^{27}$ This is based on evidence from $>20$ years ago. ${ }^{28}$ Guidelines indicate that an incidence of $\geq 1.5 \%$ /year would warrant surveillance of HCC in cirrhotic and $0.2 \%$ /year in non-cirrhotic patients.

Table 3 Summary of guideline recommendations on surveillance of non-cirrhotic patients

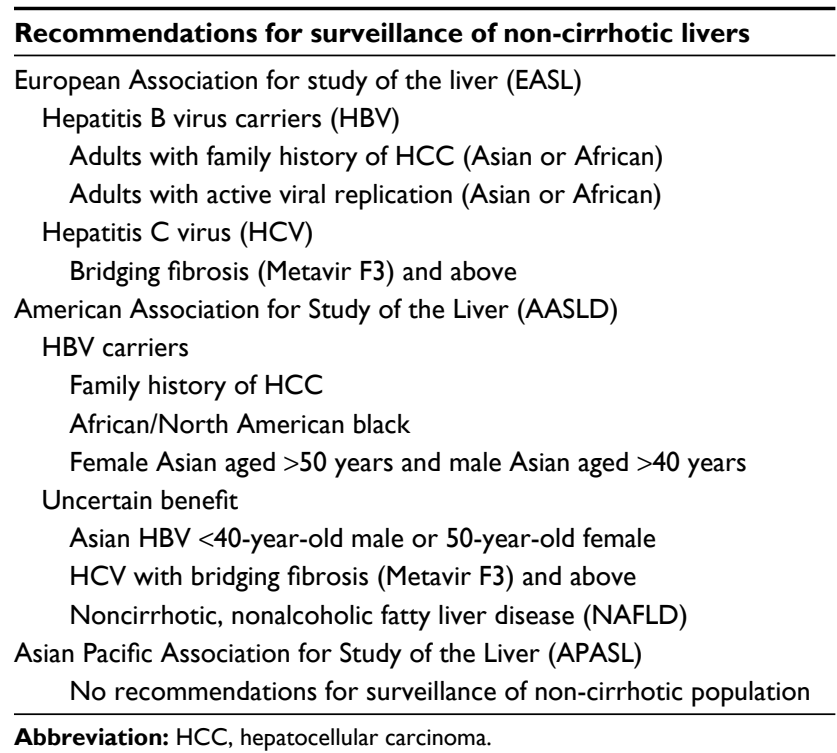

Table 4 Factors associated with increased risk of HCC based on interpretation of recently published risk prediction models

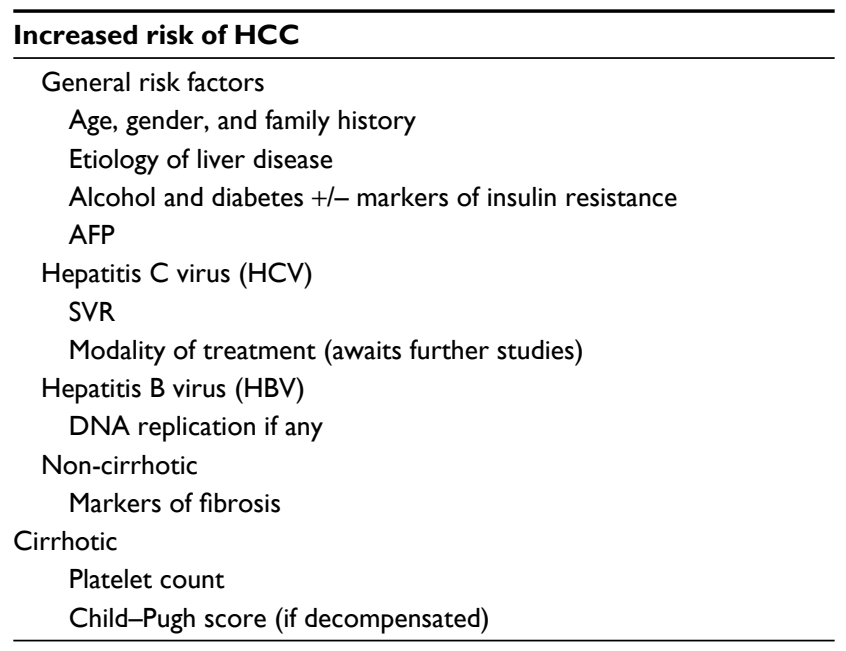

Abbreviations: AFP, alpha-fetoprotein; HCC, hepatocellular carcinoma; SVR, sustained virologic response.

The latter however is based on much weaker evidence. Such thresholds are difficult to test and implement due to various issues, for example, economical and ethical. Nomogram interpretation and subsequent decision making according to local economy as recently suggested by the French group seem more practical. ${ }^{16}$

\section{How to screen? Ultrasound}

$\mathrm{U} / \mathrm{S}$ is currently the only screening test recommended by regional liver societies as part of surveillance for HCC..$^{25-27}$ This involves firstly identifying a pre-specified patient population at relatively high risk of developing cancer and inviting them for regular screening with $\mathrm{U} / \mathrm{S}$ for early detection of cancer. This can be challenging as not all patients at risk are known to be at risk. A study on a large US veteran population cohort $(n=1,201)$ with $\mathrm{HCC}$ and liver cirrhosis found that $24.6 \%$ of the patients were not known to have liver cirrhosis prior to the diagnosis of HCC. This implies that a $100 \%$ efficient surveillance program will still miss 1 every 4 new HCCs. ${ }^{29}$ This however would be over optimistic as metaanalysis of 9 US-based studies including 17,286 patients with liver cirrhosis under regular clinical follow-up (primary, secondary, or tertiary) found that $81.6 \%$ of the patients were not practically engaged with regular surveillance for HCC. The study concluded that screening for HCC is under-utilized despite being considered as standard of care in the USA. ${ }^{30}$ Factors leading to this significant under-utilization possibly includes primary care defects, poor patient engagement, or logistical issues in test arrangements. A single tertiary 
referral center study found that only 5 out of 48 patients under regular U/S surveillance for HCC understood the reason for having a regular $\mathrm{U} / \mathrm{S} .{ }^{31}$ As a result, this implies that a $100 \%$ efficient screening test will be practically utilized by only $15 \%$ of the patients who need it. In addition, the sensitivity of $\mathrm{U} / \mathrm{S}$ is not $100 \%$. In a meta-analysis of prospective studies on 1,514 patients, the pooled sensitivity of U/S was $63 \% .^{32}$ This relatively low sensitivity has a number of potential explanations, as follows:

1. Performer variations and inter-rater reliability.

2. Patient factors including obesity and gaseous distension.

3. Tumor factors including location and echogenicity.

4. Factors related to background liver with a heterogeneous pattern in macronodular cirrhosis or severe steatosis.

Despite such difficulties, the widespread use of U/S surveillance appears to have had a large impact on HCC in the two decades as summarized in the next section.

\section{Biomarkers}

AFP is an alpha-globulin, originally detected in serum of a patient with HCC in Russia. ${ }^{33}$ AFP is typically raised in advanced HCC. On meta-analysis, the use of AFP alongside U/S scanning increased the sensitivity of HCC detection from $63 \%$ to $69 \% .^{32}$ The specificity improves only on raising cut-off values to levels around $400 \mathrm{ng} /$ $\mathrm{mL}$. Its incorporation in surveillance programs is not part of most current regional liver society guidance. ${ }^{25-27}$ It is, however, still endorsed by national guidance in the $\mathrm{UK}^{34}$ and Japan. ${ }^{35}$

More recently, the strength of evidence on the prognostic role of AFP is increasing. First, Hoshida et al associated AFP with poor prognosis of $\mathrm{HCC}$ on transcriptomal analysis. ${ }^{36}$ This was followed by Duvoux et al who published a landmark study demonstrating that HCC outside Milan criteria will have relatively good prognosis if AFP is not elevated and vice versa. ${ }^{37}$ Due to its high impact and clinical relevance, this was quickly incorporated into the UK transplant rules where AFP $>1,000 \mathrm{IU} / \mathrm{mL}$ is an absolute contraindication for liver transplantation.

The following biomarkers have been tested but none have been incorporated into routine clinical practice.

1. Des-gamma-carboxy prothrombin also known as prothrombin induced by vitamin $\mathrm{K}$ absence II (PIVKA II)

2. Ratio of glycosylated to total AFP (L3 AFP)

3. Alpha fucosidase

4. Glypican 3
Currently, there are no genomic-based biomarkers available for diagnosis of HCC. This could be related to the scarcity of genomic alterations in $\mathrm{HCC}$ at the early stages as outlined in Figure 1. Some promising future markers are outlined in the next section.

\section{Screening intervals}

The recommended screening interval in the Western world is 6 months. Some guidelines have recommended screening is performed every 3 months specifically for "very high-risk" patients, for example, cirrhotic HBV with high viral replication although the evidence on which this was based is scarce. ${ }^{35}$ There is a large patient variability in incidence and volume doubling time of HCC and theoretically a 6-month period may be too long for some patients to have their HCC detected at an early stage. A large multicenter controlled trial in France randomized cirrhotic patients to three monthly $(n=640$, mean follow-up of 47 months) or six monthly ( $n=638$, mean followup of 46 months) surveillance for HCC. Three monthly surveillance detected more $<10 \mathrm{~mm}$ focal lesions that required further surveillance. This however led to more investigations to follow-up those nodules with no significant overall increase in diagnosing HCC in comparison to the six-monthly group. There was no difference in survival between both groups. The majority of patients ( $>83 \%$ ) included in this European study were HCV and alcohol-related liver disease.

In summary, a six-monthly interval of screening is endorsed the Western world and there is RCT evidence to suggest that there is no benefit in more frequent scanning. The recall logistics and patient compliance play a major role in the actual utilization of surveillance. In the next section we review possibilities to improve recall.

\section{Impact of U/S surveillance}

In the management of $\mathrm{HCC}$, there is seemingly an implicit sharp cutting edge between patients suitable for curative therapies at diagnosis and those who are not. Larger multicenteric tumors have high rates of recurrence if treated with a curative intention. Therefore, the stage of HCC at diagnosis is crucial in predicting prognosis.

The impact of surveillance is demonstrated on comparing the HCC staging system used in the 80 s published by Okuda et $\mathrm{al}^{38}$ with the current widely used Barcelona Clinic Liver Cancer (BCLC) staging system. ${ }^{39}$ The Okuda staging system evaluated tumor size according to whether it involves more or less than $50 \%$ of the total volume of the liver in contrast to the BCLC published almost three decades later and evaluates nodules as little as $2 \mathrm{~cm}$. 
There is only one large population-based controlled trial randomizing patients between no surveillance and surveillance with U/S and AFP. The study was performed on $18,816 \mathrm{HBV}$ patients from a single village in Shanghai with 5 -year follow-up. Half the patients were randomized to either surveillance with U/S and AFP or no surveillance. It showed a significant improvement in survival of the patients within the surveillance group. HCC mortality rate in the surveillance group was $83.2 / 100 \mathrm{~K}$ versus $131.5 / 100 \mathrm{~K}$ for controls, with a mortality rate ratio of 0.63 (95\% CI: $0.41-0.98){ }^{40}$

\section{The future of screening and surveillance}

$\mathrm{U} / \mathrm{S}$ of high-risk patients remains the recommended modality for screening in the absence of reliable biomarkers in $\mathrm{HCC}$ but this is clearly inadequate with a major need for new screening tools. Such developments seem some way off so currently the focus will remain on optimizing U/S usage as a screening test.

High-risk patients who are not yet diagnosed or identified as high risk with liver cirrhosis will not be included into surveillance programs and, therefore, cannot benefit. This means a key strategy for improving cancer detection must be to increase the proportion of patients in whom a diagnosis of cirrhosis is made. Because previously a diagnosis was only able to be made on liver biopsy or on imaging in those with advanced liver disease, a high proportion of patients with liver cirrhosis will remain undiagnosed in the community. In Nottingham, we increased the number of diagnosed compensated cirrhosis in the community by $140 \%$ using noninvasive measures of fibrosis in asymptomatic but high-risk patients and this seems the most likely type of strategy to enhance identification and therefore to be able to screen a higher proportion of high-risk people. ${ }^{41}$

Noninvasive measures of fibrosis were recently reviewed by Chin et $\mathrm{a}^{42}$ and are objective and easy to perform in primary care. Similarly, many patients will have routine liver function tests (LFTs) performed during primary care visits or non-liver-related admissions to hospital. We previously published a risk stratification model that would predict future liver disease based on a scoring system which includes age, gender, LFTs, deprivation status, and alcohol intake. ${ }^{43}$ Improved primary care diagnostic pathways of subclinical liver cirrhosis has the potential to limit the burden of complications, not only HCC but also variceal bleeding and others.

To optimize HCC surveillance, physicians need to work in close partnership with their patients as there is evidence that this will improve compliance and outcome. Better patient education by specialist nurses, official education websites, patient groups, education screencasts, and smart phone applications is part of modernization of patient management pathways, replacing noninteractive and static patient leaflets. Patient engagement in clinical decision making and an active role in deciding whether or not they require HCC surveillance are strongly recommended.

Liver cirrhosis can cause multiple complications and currently patients may be advised to visit the hospital frequently for investigations and consultations. This may lead to poor compliance. One-stop clinics had successful outcomes with other specialties, for example, in patients presenting with symptoms of heart failure. ${ }^{44} \mathrm{~A}$ similar model offering educational sessions, clinical consultation, dietician review, alcohol liaison service input, U/S, TE, and endoscopy for liver patients on the same day may be much more convenient for the patient and enhance uptake of screening but there is currently no evidence to quantify this.

\section{Investigating new biomarkers of HCC}

Recent next-generation sequencing (NGS) studies have shown that genomic changes in HCC evolve in a stepwise fashion paralleling the phenotypic changes. ${ }^{45}$ There are a large number of mutations known to occur in HCC however these are mostly detected at a late stage and each occurring in relatively low frequencies. Recent NGS studies however showed relatively high-frequency TERT mutations in early HCC and some dysplastic nodules. ${ }^{46}$

Living cells frequently shed DNA which circulates freely in the plasma. Cancer cells among other living cells will do the same. Therefore, a proportion of plasma cellfree DNA (cfDNA) will harbor specific genomic features unique to the tumor, known as circulating tumor DNA (ctDNA). Similarly, some whole tumor cells will shed into the blood stream and become circulating tumor cells (CTCs) both of which provide potential targets as early diagnostic tests. Pilot studies have investigated mutations in the plasma of patients with HCC. Targeted NGS of common HCC mutations (TERT, TP53, and CTNNB1) in tumor and plasma-matched DNA of 41 patients were performed. Tumor-associated mutations were detectable in $19.5 \%$ of the plasma samples. ${ }^{47}$ There is also evidence that there is a directly proportional relationship between the concentration of ctDNA detected in plasma and cancer progression. ${ }^{48}$ The group from Newcastle has also recently optimized methodologies for characterization of CTCs in HCC. ${ }^{49}$ Circulating tumor cells and DNA are an exciting new potential and further investigations into their role as diagnostic biomarkers is awaited. 
In summary, this review serves to provide insight into issues regarding surveillance of patients at risk of developing HCC. Risk stratification and optimization of patient management pathways have been discussed with focus on tools with potential for rapid clinical applicability. Genomic-based biomarker research is an exciting future advancement, which requires detailed investigations.

\section{Acknowledgments}

This article was supported by the National Institute of Health Research Nottingham Digestive Diseases Biomedical Research Unit (NDDBRU). The views expressed are those of the author(s) and not necessarily those of the National Health Service, the NIHR, or the Department of Health.

\section{Disclosure}

The authors report no conflicts of interest in this work.

\section{References}

1. Ferlay J, Soerjomataram I 1st, Dikshit R, et al. Cancer incidence and mortality worldwide: sources, methods and major patterns in GLOBOCAN 2012. Int J Cancer. 2014;136(5):E359-E386.

2. Cancer Research UK. CRUK-Cancer mortality for common cancers. 2011. Available from: http://www.cancerresearchuk.org/cancer-info/ cancerstats/mortality/cancerdeaths/\#source1. Accessed December 8, 2013.

3. Ha J, Yan M, Aguilar M, et al. Race/ethnicity-specific disparities in cancer incidence, burden of disease, and overall survival among patients with hepatocellular carcinoma in the United States. Cancer. 2016;122(16):2512-2523.

4. Conti F, Buonfiglioli F, Scuteri A, et al. Early occurrence and recurrence of hepatocellular carcinoma in HCV-related cirrhosis treated with direct-acting antivirals. J Hepatol. 2016;65(4):727-733.

5. Kozbial K, Moser S, Schwarzer R, et al. Unexpected high incidence of hepatocellular carcinoma in cirrhotic patients with sustained virologic response following interferon-free direct-acting antiviral treatment. $J$ Hepatol. 2016;65(4):856-858.

6. Reig M, Mariño Z, Perelló C, et al. Unexpected high rate of early tumor recurrence in patients with $\mathrm{HCV}$-related $\mathrm{HCC}$ undergoing interferonfree therapy. J Hepatol. 2016;65(4):719-726.

7. Cardoso H, Vale AM, Rodrigues S, et al. High incidence of hepatocellular carcinoma following successful interferon-free antiviral therapy for hepatitis C associated cirrhosis. J Hepatol. 2016;65(5): 1070-1071.

8. Cheung MCM, Walker AJ, Hudson BE, et al. Outcomes after successful direct-acting antiviral therapy for patients with chronic hepatitis $\mathrm{C}$ and decompensated cirrhosis. J Hepatol. 2016;65(4):741-747.

9. Yuen M-F, Tanaka Y, Fong DY-T, et al. Independent risk factors and predictive score for the development of hepatocellular carcinoma in chronic hepatitis B. J Hepatol. 2009;50(1):80-88.

10. Wong VW-S, Chan SL, Mo F, et al. Clinical scoring system to predict hepatocellular carcinoma in chronic hepatitis B carriers. J Clin Oncol. 2010;28(10):1660-1665.

11. Yang HI, Yuen MF, Chan HL, et al. Risk estimation for hepatocellular carcinoma in chronic hepatitis B (REACH-B): development and validation of a predictive score. Lancet Oncol. 2011;12(6):568-574.

12. Wong GL, Chan HL, Wong CK, et al. Liver stiffness-based optimization of hepatocellular carcinoma risk score in patients with chronic hepatitis B. J Hepatol. 2014;60(2):339-345.
13. Lee HW, Yoo EJ, Kim BK, et al. Prediction of development of liverrelated events by transient elastography in hepatitis B patients with complete virological response on antiviral therapy. Am J Gastroenterol. 2014;109(8):1241-1249.

14. Jung KS, Kim SU, Song K, et al. Validation of hepatitis B virus-related hepatocellular carcinoma prediction models in the era of antiviral therapy. Hepatology. 2015;62(6):1757-1766.

15. Papatheodoridis G, Dalekos G, Sypsa V, et al. PAGE-B predicts the risk of developing hepatocellular carcinoma in Caucasians with chronic hepatitis B on 5-year antiviral therapy. J Hepatol. 2016; 64(4):800-806.

16. Ganne-Carrié N, Layese R, Bourcier V, et al. Nomogram for individualized prediction of hepatocellular carcinoma occurrence in hepatitis C virus cirrhosis (ANRS CO12 CirVir). Hepatology. 64(4): 1136-1147.

17. Lok AS, Seeff LB, Morgan TR, et al. Incidence of hepatocellular carcinoma and associated risk factors in hepatitis C-related advanced liver disease. Gastroenterology. 2009;136(1):138-148.

18. El-Serag HB, Kanwal F, Davila JA, Kramer J, Richardson P. A new laboratory-based algorithm to predict development of hepatocellular carcinoma in patients with hepatitis $\mathrm{C}$ and cirrhosis. Gastroenterology. 2014;146(5):1249-1255.

19. White DL, Richardson P, Tayoub N, Davila JA, Kanwal F, El-Serag HB. The updated model: an adjusted serum alpha-fetoprotein-based algorithm for hepatocellular carcinoma detection with hepatitis $\mathrm{C}$ virus-related cirrhosis. Gastroenterology. 2015;149(7):1986-1987.

20. Chang $\mathrm{KC}$, Wu YY, Hung $\mathrm{CH}$, et al. Clinical-guide risk prediction of hepatocellular carcinoma development in chronic hepatitis $\mathrm{C}$ patients after interferon-based therapy. Br J Cancer. 2013;109(9): 2481-2488.

21. Flemming JA, Yang JD, Vittinghoff E, Kim WR, Terrault NA. Risk prediction of hepatocellular carcinoma in patients with cirrhosis: the ADRESS-HCC risk model. Cancer. 2014;120(22):3485-3493.

22. Aoki T, Iijima H, Tada T, et al. Prediction of development of hepatocellular carcinoma using a new scoring system involving virtual touch quantification in patients with chronic liver diseases. $J$ Gastroenterol. 2016;52(1):104-112.

23. Michikawa T, Inoue M, Sawada N, et al. Development of a prediction model for 10-year risk of hepatocellular carcinoma in middle-aged Japanese: Tte Japan public health center-based prospective study Cohort II. Prev Med (Baltim). 2012;55(2):137-143.

24. Hung YC, Lin CL, Liu CJ, et al. Development of risk scoring system for stratifying population for hepatocellular carcinoma screening. Hepatology. 2015;61(6):1934-1944.

25. Omata M, Lesmana LA, Tateishi R, et al. Asian pacific association for the study of the liver consensus recommendations on hepatocellular carcinoma. Hepatol Int. 2010;4(2):439-474.

26. Bruix J, Sherman M. Management of hepatocellular carcinoma: an update. Hepatology. 2011;53(3):1020-1022.

27. EASL-EORTC. EASL-EORTC clinical practice guidelines: management of hepatocellular carcinoma. J Hepatol. 2012;56(4):908-943.

28. Laupacis A, Feeny D, Detsky AS, Tugwell PX. How attractive does a new technology have to be to warrant adoption and utilization? Tentative guidelines for using clinical and economic evaluations. CMAJ. 1992;146(4):473-481.

29. Walker M, El-Serag HB, Sada Y, et al. Cirrhosis is under-recognised in patients subsequently diagnosed with hepatocellular cancer. Aliment Pharmacol Ther. 2016;43(5):621-630

30. Singal AG, Yopp A, S Skinner C, Packer M, Lee WM, Tiro JA. Utilization of hepatocellular carcinoma surveillance among American patients: a systematic review. J Gen Intern Med. 2012;27(7):861-867.

31. Kapur NK, Musunuru K. Clinical efficiency and safety of statins in managing cardiovascular risk. Vasc Health Risk Manag. 2008;4(2):341-353.

32. Singal A, Volk ML, Waljee A, et al. Meta-analysis: surveillance with ultrasound for early-stage hepatocellular carcinoma in patients with cirrhosis. Aliment Pharmacol Ther. 2009;30(1):37-47. 
33. Tatarinov Lus. обнаружение эмбриоспецифического а- глобулина в сыворотке кровибольного первичаым раком печени [Detection of embryo-specific alpha-globulin in the blood serum of a patient with primary liver cancer]. Vopr Med Khim. 1964;10:90-91. Russian.

34. NICE_GDC. Hepatitis B (chronic): diagnosis and management of chronic hepatitis B in children, young people and adults. 2013. Available from: http://publications.nice.org.uk/hepatitis-b-chronic-cg165. Accessed December 19, 2013

35. Kokudo N, Hasegawa K, Akahane M, et al. Evidence-based clinical practice guidelines for hepatocellular carcinoma: The Japan Society of Hepatology. Hepatol Res. 2015;45(2):123-127.

36. Hoshida Y, Nijman SMB, Kobayashi M, et al. Integrative transcriptome analysis reveals common molecular subclasses of human hepatocellular carcinoma. Cancer Res. 2009;69(18):7385-7392.

37. Duvoux C, Roudot-Thoraval F, Decaens T, et al. Liver transplantation for hepatocellular carcinoma: a model including $\alpha$-fetoprotein improves the performance of Milan criteria. Gastroenterology. 2012;143(4):986-994.

38. Okuda K, Ohtsuki T, Obata H, et al. Natural history of hepatocellular carcinoma and prognosis in relation to treatment. Study of 850 patients. Cancer. 1985;56(4):918-928.

39. Forner A, Llovet JM, Bruix J. Hepatocellular carcinoma. Lancet. 2012;379(9822):1245-1255.

40. Zhang B-H, Yang B-H, Tang Z-Y. Randomized controlled trial of screening for hepatocellular carcinoma. J Cancer Res Clin Oncol. 2004;130(7):417-422.

41. Harman DJ, Ryder SD, James MW, et al. Direct targeting of risk factors significantly increases the detection of liver cirrhosis in primary care: a cross-sectional diagnostic study utilising transient elastography. $B M J$ Open. 2015;5(4):e007516.
42. Chin JL, Pavlides M, Moolla A, Ryan JD. Non-invasive markers of liver fibrosis: adjuncts or alternatives to liver biopsy? Front Pharmacol. 2016;7:159.

43. McLernon DJ, Donnan PT, Sullivan FM, et al. Prediction of liver disease in patients whose liver function tests have been checked in primary care: model development and validation using population-based observational cohorts. BMJ Open. 2014;4(6):e004837-e004837.

44. Andrea R, Falces C, Sanchis L, Sitges M, Heras M, Brugada J. Diagnóstico de la insuficiencia cardíaca con fracción de eyección preservada o reducida mediante una consulta de alta resolución [Diagnosis of heart failure with preserved or reduced ejection fraction in a one-stop clinic]. Atención Primaria. 2013;45(4):184-192. Spanish.

45. Zucman-Rossi J, Villanueva A, Nault J-C, Llovet JM. Genetic landscape and biomarkers of hepatocellular carcinoma. Gastroenterology. 2015;149(5):1226-1239.

46. Nault JC, Calderaro J, Di Tommaso L, et al. Telomerase reverse transcriptase promoter mutation is an early somatic genetic alteration in the transformation of premalignant nodules in hepatocellular carcinoma on cirrhosis. Hepatology. 2014;60(6):1983-1992.

47. Liao W, Yang H, Xu H, et al. Noninvasive detection of tumor-associated mutations from circulating cell-free DNA in hepatocellular carcinoma patients by targeted deep sequencing. Oncotarget. 2016; 7(26):40481-40490

48. Tang JC, Feng YL, Guo T, Xie AY, Cai XJ. Circulating tumor DNA in hepatocellular carcinoma: trends and challenges. Cell Biosci. 2016; 6:32.

49. Ogle LF, Orr JG, Willoughby CE, et al. Imagestream detection and characterisation of circulating tumour cells-A liquid biopsy for hepatocellular carcinoma? J Hepatol. 2016;65(2):305-313.
Journal of Hepatocellular Carcinoma

\section{Publish your work in this journal}

The Journal of Hepatocellular Carcinoma is an international, peerreviewed, open access journal that offers a platform for the dissemination and study of clinical, translational and basic research findings in this rapidly developing field. Development in areas including, but not limited to, epidemiology, vaccination, hepatitis therapy, pathology and

\section{Dovepress}

molecular tumor classification and prognostication are all considered for publication. The manuscript management system is completely online and includes a very quick and fair peer-review system, which is all easy to use. Visit http://www.dovepress.com/testimonials.php to read real quotes from published authors. 